\title{
$\underline{\mathrm{O} J \mathrm{ED}}$
}

Volume 5, Issue 1 (2020), pp. 17-33

International Journal of

Multidisciplinary Perspectives in Higher Education

ISSN: 2474-2546 Print/ ISSN: 2474-2554 Online

https://ojed.org/jimphe

\section{Invite Students to Skip the Unemployment Line: How health information management education (HIM) programs can increase employability with support from HIM stakeholders}

Aerian Tatum

Coppin State University in Baltimore, Maryland, USA

\begin{abstract}
Students graduate from accredited programs every year with skills and competencies required by the academic program of choice. However, industry leaders and educators have different perceptions as it relates to graduate preparedness for the workforce. The topic of this research study was the employability of health information management (HIM) undergraduates. This paper posited that university connections and partnerships will assist graduates in securing employment and other required skills after graduation. The purpose of this paper was to extend the work begun by Jackson, Lower, and Rudman, finding evidence via a systematic review of the literature. The question explored was how management frameworks can bridge the gap in HIM education and increase graduate employability by partnering with healthcare organizations. A systematic review methodology was used to aggregate the data from 21 articles. The findings showed it was important to consider both hard and soft skills in when increasing graduate employability. Recommendations were made for each of the actors in this situation, the educator, the undergraduate student, and the HIM industry leader/employer.
\end{abstract}

Keywords: employability, health information management, Partnership in Pedagogy, Accreditation and Collaboration (P-PAC), university industry linkage (UIL), work integration learning (WIL), soft skills 
Forty-one percent of recent undergraduates are underemployed, according to December 2019 data from the New York Federal Reserve Bank of New York. In health services, the underemployment rate jumps to $45.7 \%$, while the unemployment rate is $3.1 \%$, as of December 2019 (Federal Reserve Bank of New York, 2019). The underemployment rate is defined as the share of undergraduates working in jobs that typically do not require a college degree (Federal Reserve Bank of New York 2019). HIM students graduate from accredited programs every year armed with most of the skills and competencies required by their academic program. However, the evidence showed that there is a disconnect between what educator and employers consider preapared for the HIM workforce. The problem that this research addressed is HIM undergraduate student employability. According to a study conducted by Jackson, Lower, and Rudman (2016), there is a "statistically significant difference" between what industry leaders and educators observe undergraduates knowing when entering the workforce. The purpose of this systematic review was to synthesize frameworks that will assist health information management education students, educators, and industry leaders in bridging the gap between internships/practicums to increase graduate employability. The inability of graduates to find a job is significant in that it could decrease enrollment in colleges and universities where this major exists.

\section{Background}

HIM is not a new field; ninety-two years ago, the profession started with medical record librarians providing clinical recordkeeping in healthcare facilities. Health information management is the practice of managing medical information vital to providing quality patient care, sound fiscal management of medical resources, and data governance supporting the confidentiality of patient records (CAHIIM, 2020). Management of these data includes acquisition, analysis, and protection of digital and traditional types of information. HIM professionals are key players in health informatics, healthcare information technology, and work in any area where health information is kept. The HIM field is driven by credentials.

HIM students in the United States attend an accredited college or university to earn the right to sit for either the registered health information administrator (RHIA) or the registered health information technician (RHIT) credential. The Commission on Certification for Health Informatics and Information Management (CCHIIM) establishes and enforces the standards and procedures for certification and recertification in the United States of health informatics and information management (CAHIIM, 2020). CCHIIM is a standing commission of the American Health Information Management Association (AHIMA) dedicated to assuring the competency of professionals practicing health 
informatics and information management (HIIM) (AHIMA, 2020). CCHIIM provides strategic oversight of all AHIMA certification programs (CAHIIM, 2020).

Colleges and universities that offer HIM degrees are accredited based on curricular competencies created by AHIMA. Individual HIM competencies are grouped into six domains that represent specific and similar areas of content taken from the input of the current HIM workforce. The six domains are:

1. Data Structure, Content, and Information Governance

2. Information Protection: Access, Use, Disclosure, Privacy, and Security

3. Informatics, Analytics, and Data Use

4. Revenue Cycle Management

5. Health Law \& Compliance

6. Organizational Management \& Leadership

The Commission on Accreditation for Health Informatics and Information Management (CAHIIM) oversees the execution of AHIMA's curricular competencies by implementing the standards created to monitor programs (CAHIIM, 2020). CAHIIM strives to provide the public with effective and consistent quality monitoring of health informatics and health information management programs through the maintenance of accreditation processes (CAHIIM, 2020). The Council for Excellence in Education (CEE) enhances the health information management (HIM) profession, plans for its future through education, and provides HIM professionals with a way to get involved in the process (AHIMA, 2020). The competencies, standards, and the credentialing exam for an HIM professional, making undergraduates highly marketable, yet obtaining their first job is still difficult.

The New York Federal Reserve Bank of New York (2019) calculated employment and underemployment rates based on workers age 16-65 years of age. College undergraduates are those aged 22 to 65 with a bachelor's degree or higher; recent college undergraduates are those aged 22 to 27 with a bachelor's degree or higher (Federal Reserve Bank, 2020). Sangwan and Garg (2017) describe employability in two ways: (1) the ability to get a job and (2) ensure that students can put into practice the skills, knowledge, and understanding gained from pursuing the degree. HIM students, in accredited programs, learn skills and competencies that are directly connected to healthcare, information technology, and management.

\section{Explanation of the Organizational Problem}

HIM undergraduates have a difficult time finding jobs immediately after graduation. This could be for lack of experience or a lack of the employability skills that are required by HIM employers. 
Rao's 2014 findings indicate that effective collaboration is needed among industry, faculty, students, and educational institutions. Rao (2014) also recommended that there be an integrated approach, in educational institutions, to handle unemployability. According to Hollister, Spears, Mardis, Lee, McClure, and Liebman (2017), ongoing industry input into curricula and expanded experiential opportunities may ensure that undergraduates are prepared to address current and future IT developments. Although students are prepared with the theory and concepts to perform the duties of jobs in the field, they are not purveyed the opportunity to acquire a position.

\section{Methodology}

The process of identifying and appraising empirical evidence that meets specified criteria pertinent to the research question was done through the method of a systematic review (SR). This SR was performed to determine how management frameworks bridge the gap in health information management (HIM) education and increase graduate employability by partnering with healthcare organizations. According to Gough, Oliver, and Thomas (2012), "systematic reviews are a form of research; they are a way of bringing together what is known from the research literature using explicit and accountable methods" (p. 2). Systematic reviews are a scientific evidence-based methodology. The SR methodology enables the research to merge relevant research literature by using a rigorous and transparent process (Gough, Oliver, \& Thomas, 2012 , p.6). The cornerstone of evidence-based management is the wellexecuted systematic review that explicitly summarizes what is known and unknown about a specific practice-related research question (Briner, Denyer \& Rousseau, 2009). A search strategy was crafted based on the RQ themes and concepts to gather the literature used for this SR.

\section{Search Strategy/Data Collection}

The RQ examined the literature of P-PAC, Knowledge Transfer (KT), University-Industry Linkage (UIL), and Work Integration Learning (WIL) in the field of HIM. Immediately, The Journal of AHIMA and Perspectives in HIM were searched for relevant articles. The following table depicts the search strings used. All available UMGC databases were used in each search. The asterisk was used at the end of the search string as a truncation symbol. This symbol is used to include single and plural endings of literature titles.

\section{Table 1}

Search Strings

\begin{tabular}{|c|c|c|c|}
\hline Number & Search String & Database & $\begin{array}{c}\text { Number of Items } \\
\text { Returned }\end{array}$ \\
\hline
\end{tabular}




\begin{tabular}{|c|c|c|c|}
\hline 1 & $\begin{array}{l}\text { (knowledge } \\
\text { management AND } \\
\text { university or college or } \\
\text { higher education AND } \\
\text { apprenticeship or } \\
\text { internship) }\end{array}$ & \multirow{4}{*}{$\begin{array}{l}\text { UMGC's } \\
\text { OneSearch }\end{array}$} & 1089 \\
\hline 2 & $\begin{array}{l}\text { Work-integrated } \\
\text { learning AND } \\
\text { employment }\end{array}$ & & 555 \\
\hline 3 & $\begin{array}{l}\text { university industry } \\
\text { linkage AND } \\
\text { employment }\end{array}$ & & 314 \\
\hline 4 & $\begin{array}{l}\text { knowledge transfer and } \\
\text { employability }\end{array}$ & & 92 \\
\hline 5 & $\begin{array}{l}\text { P-PAC Partnership in } \\
\text { Pedagogy, } \\
\text { Accreditation, and } \\
\text { Collaboration }\end{array}$ & Google Scholar & 2 \\
\hline
\end{tabular}

Search strings one through four were conducted with the University of Maryland Global Campus' (UMGC) OneSearch. Search string one returned 1,089 results using the Boolean operator AND. This operator helps to narrow results and informs the database that all search terms must be present in the resulting records. Search string two returned 555 results using the Boolean operator AND. Search string three returned 314 results with the Boolean operator AND. Search string four returned 92 results. Search string five was performed using Google Scholar and returned two results. Google Scholar was utilized for this search to find an assortment of materials, including articles and "grey literature" like conference proceedings. All searches utilized requested publications between 2015 and 2020. All searches were limited to peer review/scholarly journals. Articles that were specific to HIM or allied health, employability, internships, and practicums were included, while articles that did not were excluded. Articles that included the frameworks P-PAC, Knowledge Transfer (KT), University-Industry Linkage (UIL), and Work Integration Learning (WIL) were included regardless of the year. Articles that did not mention these frameworks were excluded.

\section{Critical Appraisal}

Each article was assessed for transparency, accuracy, purposivity, utility, propriety, accessibility, and specificity (TAPUPAS) on a threepoint scale (completely met, somewhat met, and not at all met) (Pawson, Boaz, Grayson, Long, \& Barnes, 2003). TAPUPAS demonstrates an element of rigor in the SR process. Measuring articles by similar domain 
and scale ensures that each was measured against similar criteria and that their inclusion in the systematic review is purposeful.

Transparency was assessed by examining whether each article described the methods clearly enough for replication and understanding. Further, was the author open to scrutiny, and did they discuss their study's limitations. Accuracy was assessed by looking at whether their results and implications were realistic, given their study design and implementation of it. Also, was there appropriate use of the previous studies they were citing as evidence for their claims and direction. The criteria focused on whether the design and approach were appropriate for their research purpose or hypothesis to assess purposivity. It should be noted that both accuracy and purposivity measure elements of rigor, which are the design and methods that keep the research as unbiased as possible and demonstrates a good fit for purpose. The utility was assessed by examining whether the knowledge generated was useful to the intended audience. For propriety, the criteria focused on whether the authors cited when appropriate and whether they were making claims that could be potentially harmful should someone implement their implications. The readability of the article, the presentation style of the information, and whether the authors explained the data in a way that was accessible to the target audience used to assess accessibility. Lastly, for specificity, would the research or article meet the expectations of the field in design, methods, and implication assessment?

Each of the 21 articles that remained after the screening for this systematic review was measured using these assessment criteria. The articles that scored the lowest using TAPUPAS were excluded from the subsequent coding and synthesis.

\section{Data Extraction}

Data were extracted from the articles by using analytic memoing for the first cycle coding. Analytic memoing is a note-taking method that parallels blogging or journaling (Groenewald, 2018). Analytic memoing allows the researcher to gather research thoughts and data (Groenewald, 2018). A free-flowing note-taking process, analytic memoing, was utilized to capture themes and understand the articles completely.

Theoretical coding was used to code the articles on the second cycle coding. Theoretical coding, also known as selective coding or conceptual coding, establishes an overarching code that incorporates all the codes and categories that emerged from the data; the entire set of codes and categories then "become systematically integrated around the central/core category, the one that suggests a theoretical explanation for the phenomenon" (Saldaña, 2016, p. 250). There are ten emerging themes: learning, work, graduate(s) work-integrated learning, university industry 
linkage, Partnership in Pedagogy, Accreditation, and Collaboration (PPAC), employ/employability, internship, practicum, and apprenticeship.

\section{Study Selection}

In this section, synthesis was performed to integrate relevant knowledge and research findings from the research question. Rigor was demonstrated by triangulating data and providing multiple sources of data to draw conclusions. Each of the studies provided a wealth of information to appropriately defend their claims. When creating a research question, it is important to use a framework to help form a good question. CIMO is a framework that requires the writer to focus on the content, intervention, mechanisms, and outcomes of the research question. According to Denyer and Tranfield (2009), a "well-formulated review question in management and organization studies need to take into account why or how the relationship occurs and in what circumstances" (p. 682). The selected articles all help to answer the research question: how can management frameworks bridge the gap in health information management (HIM) education and increase graduate employability by partnering with healthcare organizations? Figure 2 depicts CIMO for the research question.

\section{Figure 2}

\section{CIMO}

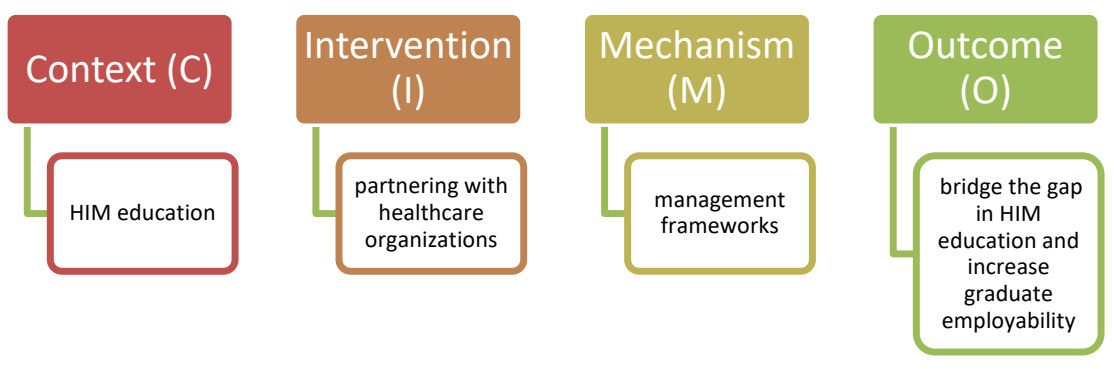

\section{Theoretical Frame}

Knowledge management (KM) aligns with university approaches to educating students on the competencies required by accrediting bodies and professional organizations. $\mathrm{KM}$ is defined as getting the right knowledge to the right person at the right time (Hajric, 2018). The overarching goal of KM is to leverage and refine the knowledge assets of undergraduates to meet organizational goals. Knowledge transfer refers to sharing or disseminating knowledge and providing inputs to problemsolving. Transferring the concepts and competencies learned during the student's college tenure is paramount for increased employability.

In the spirit of KM, getting the right education to the right person, KT allows students to transform that knowledge into practice with 
vendors and healthcare organizations during their internships, practicums, and/or apprenticeships (IPAs). HIM IPAs are usually conducted at traditional healthcare settings such as hospitals, healthcare clinics, and doctors' offices. IPAs may also be in unusual settings such as prisons and healthcare consulting firms. Armed with their arsenal of professional competencies, innovative scholarship, and technical abilities, students are prepared for IPAs.

Employers look forward to the fresh perspective and ideas from students entering the field. Wrye, Chafin, and Higginbotham (2019) posit the partnership and collaboration between community organizations and educational establishments is an important conduit in community and public health student's employability skills (p.606). Through the lens of knowledge management, knowledge transfer seeks to organize, create, capture, or distribute knowledge and ensure its availability for future users (Hajric, 2018). Knowledge transfer will be reciprocal when creating increased graduate employability. Employability requires a set of skills that could direct the individuals to get employed, maintain being employed, and even possibly become self-employed and create jobs (Majid, 2016). The research showed that frameworks such as Partnerships in Pedagogy Accreditation and Collaboration (P-PAC), Work-Integrated Learning (WIL), and University-Industry Linkage (UIL) increases employability skills in recent undergraduates.

As mentioned above, HIM education is the foundation for all students accepted into accredited programs. Accredited HIM programs are governed by the competencies created by AHIMA and maintained with standards created by CAHIIM. Figure 1 depicts the strategy for increased employability for HIM undergraduates. The scholastic curriculum is considered the origin of the HIM student's education. A strong curriculum is crucial to the health and longevity of the major. At the origin of the HIM students' education, the construct of KM, KT, is used to take the knowledge gained from HIM education to translate theory into practice within internships and practicums to increase employability.

Figure 1: A conceptual model for HIM education strategies for increased employability 


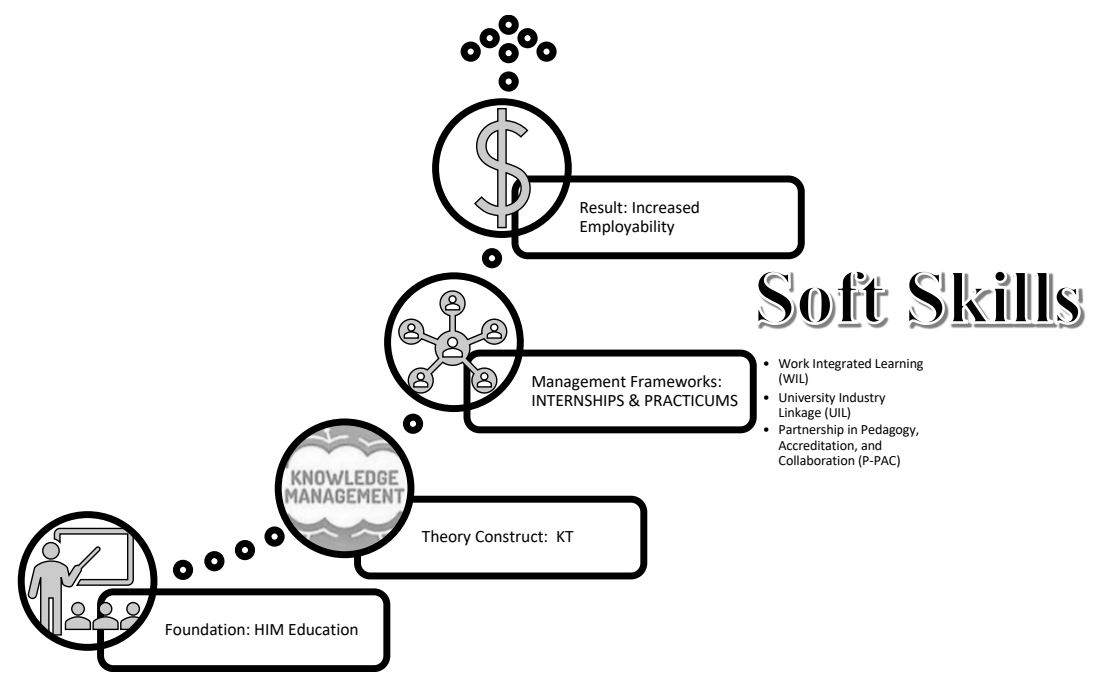

Note: Strategy for increased employability for HIM undergraduates

\section{Results}

\section{Current Methods of Knowledge Transfer}

The findings show HIM students currently transfer knowledge to practice via internships, practicums, and apprenticeships. However, this ability does not equate to increased employability after graduation, as evidenced by the study conducted by the Federal Reserve Bank of New York (2019). Coco (2000), Jackson et al. (2016), and Ripamonti, Galuppo, Bruno, Ivaldi, and Scaratti (2018) believe that internships assist with preparing students for real-world experience in a learning environment. Internships, as explained by Ripamonti et al. (2018), provide students with an opportunity to integrate academic learning with 'real-world' experience, to integrate action and reflection, and to integrate formalized and procedural knowledge. Rao (2014) posits that effective collaboration is needed among industry, faculty, students, and educational institutions. Gardiner and Salmon (2014) discuss urban teacher residencies (UTR) to bridge the theory and practice gap and is an excellent example of increasing graduate employability. The authors posit UTRs help undergraduates secure teaching positions in partnering districts and provide induction program support (Gardiner \& Salmon, 2014). This is demonstrative of increasing employability in HIM undergraduates with a secured position in the HIM field of study.

Internships, practicums, and apprenticeships also offer opportunities for employers. Coco (2000), along with Jackson, Lower, and Rudman (2016), agree that employers benefit from internships. Internships and apprenticeships offer employers the opportunity to observe individuals' skill sets, evaluate their strengths and weaknesses, and identify new candidates for employment (Jackson et al., 2016). Coco 
(2000) posits internships offer businesses an opportunity to recruit future employees who have proven themselves. The following frameworks are ways in which to increase employability in HIM undergraduates. The frameworks will be introduced and then compared to current practices in HIM.

\section{University Integrated Learning (UIL)}

UIL establishes a relationship between the university and industry. Ishengoma and Vaaland (2016) postulate that UILs are defined as interactions between all parts of the higher education system and industrializing economy. There are four models synonymous with UIL: research and development projects, technical training, short courses, and graduate education, and activity-based sponsoring (Ishengoma \& Vaaland, 2016). UIL uses items such as career talks, vendor exposure, education of faculty through education sabbaticals, and research collaborations to enhance the learning experience for the student; thus, making them able to secure a position after graduation.

Ishengoma and Vaaland (2016) suggest two internship modes to increase employability in students: internship adoption strategy (IAS) and the internship diffusion strategy (IDS). The difference between the two strategies is the source of the skill transfer. In IAS, the idea is to adapt existing skills and attitudes from the firm to the student to increase employability. Inversely, IDS diffuse skills from the student to the local firm to improve the competitiveness of the firm and increase the employability of the student.

\section{P-PAC}

The evidence shows that graduate employability increases when universities partner with employers. Partnership in Pedagogy, Accreditation, and Collaboration is a framework that encourages and embeds a partnership approach between academia, students, and industry (Brennan \& Dempsey, 2018). Brennan and Dempsey (2018) posit that students are better equipped when the goal is promoting collaboration, facilitating relevant curriculum with pedagogy practice, and accrediting achievement. The goal is to ensure that more engaged in learning and are students better equipped with the necessary skills for both employability to increase human capital.

Studies show that students typically view the purpose of higher education institutions (HEIs) as that of providing them with the credentials and competencies necessary for rewarding employment. PPAC framework encourages and embeds a tripartite partnership approach between academia, students, and industry(Brennan \& Dempsey, 2018). This framework promotes collaboration, facilitates curriculum and pedagogy practices, and accredits achievement to develop undergraduates 
with the attributes for employability and global citizenship(Brennan \& Dempsey, 2018). The theoretical framework for P-PAC (shown in Figure 3) involves academia, industry, and the student. Academia and industry overlap when collaboration occurs. Academia and students interact through pedagogy. Industry and the student overlap through accreditation. When the three (student, academia, and industry) overlap, that is the definition of P-PAC.

\section{Figure 3: P-PAC Theoretical Framework}

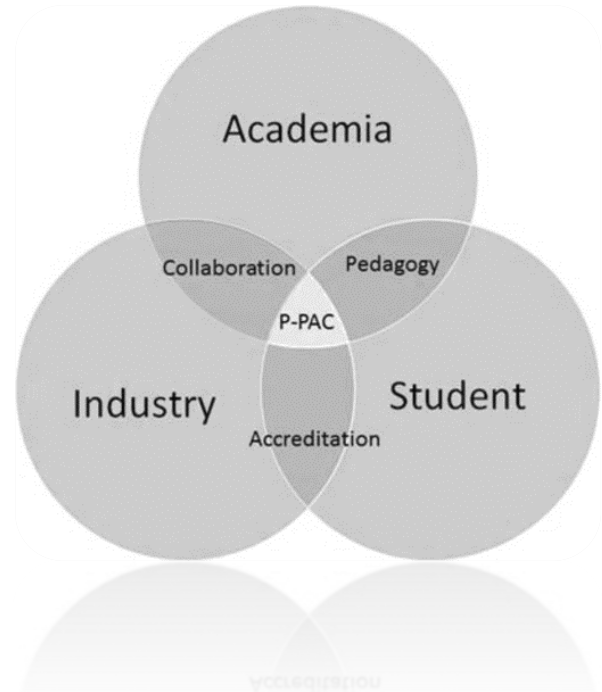

Experiential learning and work-integrated learning are used synonymously in the literature. Experiential learning is through experience, while experimental learning is via experiment. Jackson et al. (2016) posit that experimental, not experiential, learning provides an opportunity to develop by transferring in prior knowledge. Govener and Taylor (2015) theorize that experiential or work-integrated learning allows students to learn through partnerships with business, industry, and government to improve economic growth. Evidence shows that managers benefitted from the partnership in meeting national skills development imperatives (Govender \& Taylor, 2015). It is noted from the literature that employers also enjoyed screening undergraduates for full-time employment.

\section{Work Integrated Learning (WIL)}

WIL aims to increase graduate employability by integrating IPAs into the curriculum. Jones, McAllister, and Lyle (2015) explain workintegrated learning as the transition of theoretical knowledge into 
professional practice, thus preparing the student for their work following graduation. A qualitative study, written by Jones et al. (2015), indicate that students were challenged in transitioning from being observational learners and appreciated the 'real work' experiences gained from their work-integrated learning experience. This study also suggested that an opportunity to work in rural areas to increase service-learning opportunities. Nottingham (2019), similar to Jones et al., has findings that suggest that academics practitioners should collaborate with industry leaders to "embed personal, social and economic dimensions into the curriculum" (Nottingham, 2019, p. 41). Exposure to rural areas can introduce new employability opportunities for undergraduates and expose them to areas that may be unfamiliar to them.

\section{Discussion}

\section{The Frameworks Compared}

P-PAC, WIL, and UIL all similarly aim to increase graduate employability and can be implemented by incorporating a collaborative effort between the university and industry leaders. P-PAC differs from WIL and UIL in that it inserts innovative ideas, from the industry, into the school's curriculum. Brennan and Dempsey (2018) contend that the success of education lies in the application of frameworks such as P-PAC to scaffold the student-academia- industry partnership in order to 'best' prepare and equip students with both the hard and soft skills for employability. In contrast, WIL involves the placement of students into workplace settings to move individuals from being just students to becoming novice professionals (Govender \& Taylor, 2015). Student IPAs assist with this critical step of increased employability. UIL aims to include the student, faculty, and professional societies in the partnership. An equally important part of the employability process, students, faculty, and professional societies, should partner as often as possible to network and increase familiarity.

\section{Incorporating the Frameworks in HIM}

HIM has incorporated experiential learning strategies and techniques to increase the concept comprehension in students. UIL suggests that industry leaders and educators partner to offer vendor talks and vendor exposure; this is something that HIM educators do well. Currently, students are encouraged to engage with the national and state HIM associations. Vendors are invited to campuses to share industry knowledge, along with personal and professional experiences. AHIMA has an entire student section on their website. The website uncovers the profession, assists students with locating accredited programs, has an interactive career map, and highlights jobs and the job search feature.

\section{Increased Employability and Soft Skills}


Students may use internships and practicums as an opportunity to develop, enhance, and refine soft skills such as critical thinking, teamwork, and communication skills. Soft skills, business acumen, improved communication skills, and work etiquette assist recent undergraduates with securing employment after graduation (Jackson, Lower, and Rudman, 2016). Employability hinges on both the undergraduates' subject knowledge, practice, skills, and character qualities and the faculty, curriculum, and instruction in university systems, in addition to the companies who employ the undergraduates and their prospects (Tang, 2019). Soft skills are defined as those related to personal interaction and are behavioral in nature (Pang, Wong, Leung, \& Coombes, 2019). Pang et al. (2019) further state that research shows that employers place greater emphasis on soft than hard skills. It is worth saying that the lack of people, communication, and social skills, along with missing or peculiar character or personality traits, will decrease a graduate's employability. Gabor, Blaga, and Matis (2019) stated that hard and soft skills are equally as important as knowing key competencies. An undergraduates' attitude, career attributes, social intelligence, and emotional intelligence proportions are more likely to increase employability and marketability. Stellar soft skills allow undergraduates to navigate their environment, work well with others, perform well, and achieve their goals with complementing hard skills.

\section{Role Recommendations-Implications for Practice Students and Recent Undergraduates}

The studies show that students should be flexible, self-directed, and implement both soft and hard skills in the workplace. An undergraduates' attitude, career attributes, social intelligence, and emotional intelligence proportions are more likely to increase employability and marketability.

\section{Colleges and Universities}

The studies show that universities should practice transparency in disclosing the concepts and skills being taught within the curriculum. Accredited programs are committed to teaching the six domains of AHIMA's CEE competencies; however, it is up to those programs to create a robust curriculum that supports those domains. Pang et al. (2019) proved that apprenticeship programs readily available, universities, ideally supported by the government, can study, learn and then develop and implement similar programs with a clear focus on the competencies demanded by employers.

Hollister et al. (2017) and Nottingham (2019) recommend that industry input into curricula and expanded experiential opportunities may ensure that undergraduates are prepared to address current and future IT 
developments. Majid (2016) further suggests, "besides being pedagogically competent, the academics also need to become industry aware" (p.80). Collaborating with industry partners at a micro-level could enable the academics to be within the industry as much as the industry could be within the academics' classrooms (Majid, 2016). It is recommended that apprenticeship programs such as these be set up to extend into the period after graduation to bridge the gap and increase employability.

It is further recommended that soft skill lessons be implemented throughout students' tenure in HIM programs. The evidence has shown that soft skills are essential to employers. It is the responsibility of the university to ensure that students have regular soft skills training so that students exhibit a balance between soft and hard skills.

A final recommendation for HIM educators is to increase academic scholarship by writing about and publishing articles regarding the changes and updates made to their respective curricula. The research on HIM education is limited and needs to be enhanced. As it is noted in the limitations of this study, the research on HIM is not robust in HIM education.

\section{Industry Leaders and Employers}

The studies show that industry leaders and employers should attempt to understand what is being taught at accredited colleges and universities, inserting into the curriculum the soft skills and characteristics that are lacking from their perspective. Pang et al. (2019) state with the increasing demands from employers of recent undergraduates comes an increasing need for a better understanding of graduate competency requirements. As stated above, the recommendations of Hollister et al. (2017) should encourage employers to share the specialized skill sets being sought in new undergraduates. Employers and industry leaders should partner with universities to "home grow" ideal candidates to increase the employability of undergraduates.

\section{Limitations and Future Research}

This study was limited by the amount of research found related to HIM education. There appears to be limited research regarding the HIM curriculum and increasing graduate employability. Future researchers can expand on this topic by studying HIM students and their habits, specifically. The field would benefit from a study that measures how long it takes HIM students to secure a position in HIM.

Another limitation was the amount of time given to perform searches, literature reviews, and synthesis. This study was conducted for a doctorate in business administration (DBA) course; the length of the project was four weeks. Future researchers should also consider studying 
employers that home grows employees that have recently graduated from HIM programs and their success. The HIM field would benefit from the study of the rate of innovation and change in HIM undergraduate employability as it relates to the input given by employers to colleges and universities.

\section{Conclusion}

In conclusion, the SR reviewed frameworks that will assist recent HIM undergraduates with increasing their employability. In December 2019, forty-one percent of recent undergraduates are underemployed, while $3.9 \%$ of recent undergraduates were unemployed. In health services, the underemployment rate jumps to $45.7 \%$, while the unemployment rate is 3.1\%, as of December 2019 (Federal Reserve Bank of New York, 2019). Recommendations were provided based on the role of the individual in the HIM educational journey. Undergraduates are encouraged to perfect soft skills to enhance the hard skills learned in their respective programs. Universities are encouraged to share their curriculums with industry leaders and solicit feedback on the concepts being taught. Industry leaders are encouraged to adopt HIM programs. Corporations should contribute to streamlining the curriculum to standards that would allow them to employ recent undergraduates.

\section{References}

AHIMA. 2020. American Health Information Management Association. 04 24. http://www.ahima.org/about/governance/cchiim.

Association of Schools Advancing Health Professions (2020). What is allied health? http://www.asahp.org/what-is

Brennan, A., \& Dempsey, M. (2018). P-PAC (Partnership in pedagogy, Accreditation, and Collaboration): A framework to support student transition to employability in industry. A lean systems case study. Management and Production Engineering Review, 9(4), 35-47. https://doi.org/10.24425/119544

CAHIIM. 2020. The Commission on Accreditation for Health Informatics and Information Management Education (CAHIIM). 0424. http://www.cahiim.org.

Coco, M.(2000). A try before you buy arrangement. Advanced Management Journal. 65(2), 41-43+.

Briner, R. B, Denyer, D, and Rousseau, D.M. (2009). Evidence-based management: Concept cleanup time? Academy of Management Perspectives, 23, 19-32, https://doi.org/10.5465/amp.23.4.19

Denyer, D., \& Tranfield, D. (2009). Producing a systematic review. In D. A. Buchanan \& A. Bryman (Eds.), The Sage handbook of organizational research methods (pp. 671-689). Thousand Oaks, 
CA: Sage Publications Ltd.

Federal Reserve Bank. (2019). The Labor Market for Recent College

Graduates. https://www.newyorkfed.org/research/college-labor-

market/college-labor-market_underemployment_rates.html

Gabor, M.R., Blaga, P., Matis, C. (2019). Supporting employability by a

skills assessment innovative tool-Sustainable Transnational Insights

from Employers. Sustainability 2019, 11(12), 3360.

https://doi.org/10.3390/su11123360

Gardiner, W., \& Salmon, D. (2014). Bridging the Theory-Practice Gap in an

Urban Teacher Residency: Two Interventions and a Cautionary Note.

Journal of Urban Learning, Teaching, and Research, 10, 87-100.

Gough, D., Oliver, S., \& Thomas, J. (2012). An introduction to systematic reviews. London: SAGE Publications

Govender, C. M., \& Taylor, S. (2015). a Work Integrated Learning

Partnership Model for Higher Education Graduates To Gain

Employment. South African Review of Sociology, 46(2), 43-59.

https://doi.org/10.1080/21528586.2015.1009857

Groenewald, T. (2018). Memos and memoing. The SAGE Encyclopedia of

Qualitative Research Methods, 2, 505-506.

Hajric, E. (2018). Knowledge Management: A Theoretical and Practical

Guide for Knowledge Management in Your Organization.

Hollister, Spears, Mardis, Lee, McClure, and Liebman. (2017).

Employers' perspectives on new information technology technicians'

employability in North Florida. Education and Training. 59(9), 929-

945. https://doi.org/10.1108/ET-02-2017-0019

Ishengoma, E., \& Vaaland, T. I. (2016). Can university-industry linkages stimulate student employability? Education and Training, 58(1), 18-

44. https://doi.org/10.1108/ET-11-2014-0137

Jackson, K. B., Lower, C. L., \& Rudman, W. J. (2016). The crossroads between workforce and education. Perspectives In Health Information Management, Spring, 1-11.

Jones, D., McAllister, L., \& Lyle, D. (2015). Stepping out of the shadows: allied health student and academic perceptions of the impact of a service-learning experience on students' work-readiness and employability. Journal of teaching and learning for graduate employability, 6(1), 66-87.

Majid, F. (2016). Academics' Diversification Enhancing Graduate

Employability through the Scholarship of Teaching and Learning. Asian Journal of University Education, 12(2), 79-96.

Nottingham, P. (2019). Acknowledging lifelong learning principles within work-based studies: a continuing legacy for the degree apprenticeship. Widening Participation \& Lifelong Learning, 21(1), 29-45. https://doiorg.ezproxy.umuc.edu/10.5456/WPLL.21.1.29

Pang, E., Wong, M., Leung, C. H., \& Coombes, J. (2019). Competencies for 
Fresh Graduates' Success at Work: Perspectives of Employers.

Industry and Higher Education, 33(1), 55-65.

Pawson, R., Boaz, A., Grayson, L., Long, A. F., \& Barnes, C. (2003). Types and quality of social care knowledge. Stage two: Towards the quality assessment of social care knowledge (Working Paper 18). ESRC UK Centre for Evidence Based Policy and Practice. https://www.kcl.ac.uk/sspp/departments/politicaleconomy/research/ cep/pubs/papers/assets/wp18.pdf

Rao, M. (2014). Enhancing employability in engineering and management students through soft skills. Industrial and Commercial Training. 46(1), 42-48.

Ripamonti, S., Galuppo, L., Bruno, A., Ivaldi, S., \& Scaratti, G. (2018)

Reconstructing the internship program as a critical reflexive practice:

The role of tutorship, Teaching in Higher Education, 23(6), 751-768, https://doi.org/10.1080/13562517.2017.1421627

Saldaña, J. (2016). The coding manual for qualitative researchers. Los Angeles: SAGE Publications.

Sangwan, S. and Garg, S. (2017), "WIL and business graduate skill transfer to workplace", On the Horizon, Vol. 25 No. 2, pp. 109-114.

Tang, K. N. (2019). Innovate Higher Education to Enhance Graduate

Employability. Pertanika J. Soc. Sci. \& Hum, 27(3), 1727-1738.

Wrye, B., Chafin, C., Higginbotham, C. (2019). Creating a Win-Win: Designing and implementing mutually beneficial collaborations between community organizations and academic programs. Education and Training. 61(5), 605-621.

\section{Author Bio}

Aerian H. Tatum, MS, RHIA, CCS, is an assistant professor in the Health Information Management department at Coppin State University in Baltimore, Maryland. She is a Doctorate of Business Administration (DBA) candidate at the University of Maryland Global Campus. Professor Tatum's research interests include health information management, healthcare reimbursement, graduate employability, and the relationship between practitioners and college curricula. 